\title{
Quantitative Literacy Across the Curriculum: A Case Study
}

\section{Benjamin Steele}

Dept. of Natural Sciences, Colby-Sawyer College, bsteele@colby-sawyer.edu

Semra Kiliç-Bahi

Dept. of Natural Sciences, Colby-Sawyer College, skilic-bahi@colby-sawyer.edu

Follow this and additional works at: https://digitalcommons.usf.edu/numeracy

Part of the Mathematics Commons, and the Science and Mathematics Education Commons

\section{Recommended Citation}

Steele, Benjamin, and Semra Kiliç-Bahi. "Quantitative Literacy Across the Curriculum: A Case Study." Numeracy 1, Iss. 2 (2008): Article 3. DOI: http://dx.doi.org/10.5038/1936-4660.1.2.3 


\title{
Quantitative Literacy Across the Curriculum: A Case Study
}

\begin{abstract}
We describe a quantitative literacy (QL) program at Colby-Sawyer College, a small, residential, liberal arts college in New Hampshire. This program has grown rapidly from a traditional math curriculum to a college-wide understanding of quantitative literacy and voluntary participation by many faculty members in all departments. More than $80 \%$ of the faculty agreed that it would be useful for students to be able to use quantitative skills in their courses, but only $24 \%$ thought students were capable of doing very well in mathematics. Twenty-three faculty members attended a summer workshop, funded by NSF, DUE \# 0633133, in which they created QL modules for their courses. These participants represented five departments and 13 different disciplines. Modules were created in Biology, Business, Chemistry, Education, English, Environmental Studies, History, Political Science, Psychology, Sociology, and Writing. In addition to assessment of individual modules, a college-wide assessment tool will be administered to first-year students and seniors by participating faculty members. We believe that the rapid growth and success of our program is perhaps due to a combination of characteristics of our institution and our approach. These characteristics include: Involving as many people as possible from many different disciplines from the beginning; a culture of collaboration and innovation at Colby-Sawyer; a supportive administration; the support of NSF that allows concentrated and focused time for faculty with heavy teaching loads; and a faculty focus on the scholarship of teaching.
\end{abstract}

\section{Keywords}

Quantitative literacy, curriculum, liberal arts, faculty development, assessment

Creative Commons License c) (i) (9)

This work is licensed under a Creative Commons Attribution-Noncommercial 4.0 License 


\section{Introduction}

Quantitative literacy (QL) is rapidly gaining popularity in higher education. In the US, recognition of the need for QL gained acceptance in the 1990's and has spread quickly (Madison and Steen 2008). It is supported by two national professional organizations formed very recently (National Numeracy Network [NNN] and the Special Interest Group of the Mathematical Association of America on Quantitative Literacy [SIGMAA-QL] both founded in 2004). As of January 2007, the online list "Selected Quantitative Literacy Programs in U. S. Colleges and Universities" (Steen 2007) included 32 QL initiatives of various types (see also Gillman 2006; Madison and Steen 2008).

The nationwide growth of QL is paralleled by an even shorter incubation period at Colby-Sawyer College, a small, liberal arts institution in New Hampshire. Although our QL program ${ }^{1}$ is still in its infancy, it has been implemented across the curriculum and supported with a grant from the National Science Foundation (NSF, DUE \#0633133). The program relies on voluntary participation of faculty who add QL elements to their courses, and it is assessed primarily by a test given to first-year students and seniors. Our experiences at Colby-Sawyer are perhaps instructive to institutions interested in following a similar trajectory.

There are many different definitions of QL, but we have chosen a simple one: using simple mathematical concepts to solve everyday problems. We also contrast it with the unfortunate view that many students have of "math" - the ability to solve complex mathematical problems that have no apparent practical value. The need for QL is compellingly described by authors in Steen (2001) and Madison and Steen (2003). It is becoming apparent that the traditional requirement of a single math course as part of a liberal arts curriculum does not meet the needs of most of students. This is especially true if the one mathematics course a student takes is "pre-calculus" a course preparing them for another course that they may not take. Even students who have taken several math courses are often confused by calculating percentage change and converting units, for example.

Successful implementation of QL will be achieved when it is ingrained in students as a habit of mind (Hughes-Hallett 2003), where they will pull out quantitative tools to solve problems without being prompted by a professor, or even the topic of a course. This is particularly true in a liberal arts curriculum, where the emphasis is on critical thinking and life skills and not so much knowledge of particular facts and concepts. It seems intuitive to us that habits of mind cannot be taught in a single course. Students must see that QL skills in one

${ }^{1}$ http://www.colby-sawyer.edu/academic/liberaleducation/quantitative (accessed June 10, 2008) 
part of the curriculum are applicable to other subjects, and the best way to make this explicit to students is to present them with QL problems in many different areas of the curriculum (Hughes-Hallett 2003; Richardson and McCallum 2003). While students may see this as a conspiracy, that may be good, as long as they see it as a "good-natured conspiracy" (Hughes-Hallett 2001). It makes sense to teach QL across the curriculum.

\section{Need for QL at Colby-Sawyer College}

QL seemed particularly appropriate for Colby-Sawyer College. Colby-Sawyer is a small residential college that combines traditional liberal arts with professional preparation. Our 1000 students have an average SAT of around 1000 with an average quantitative SAT of 500. Many students self-report that they "are not math students." We do not have a history of attracting students interested in progressing in math, and we do not offer a math major or minor. The most advanced course we offer, Calculus I, enrolls about 12 students per year. On the other hand, quantitative concepts are regularly used in discipline courses such as biology, exercise science, psychology, business administration, and nursing. Faculty members often note that quantitative concepts are difficult for many of their students in their classes, and so the across-the-curriculum approach seemed natural to us. A recent survey verified what informal conversations had told us: more than $80 \%$ of the faculty agreed or strongly agreed that it would be useful for students to be able to use a variety of quantitative skills in their courses. However, only $24 \%$ thought students at Colby-Sawyer were capable of doing very well in mathematics.

Thus, faculty believed that students would benefit from more ability in QL. The results of this survey were verified more recently by testing students directly. We discovered that only about $40 \%$ of our students could answer questions like: "Write 56.921 as a percent." While there were no formal discussions of the lack of mathematics preparedness of our students, a concurrent campus-wide discussion of a revision in our liberal education program included revising the mathematics mission statement. That revision, which turned it into a quantitative literacy statement, focused the faculty's attention on the deficit in quantitative abilities.

As a result, there was a fairly strong incentive coming from the faculty to strengthen the quantitative skills of our students. Furthermore, an across-thecurriculum approach fit, since we had already implemented writing across the curriculum. While there are no formal course requirements in writing beyond the first-year writing course, most of the faculty attended workshops on writing in 2003-04, and now faculty members include many different kinds of writing assignments in their courses. The electronic liberal education portfolio required 
of all students is a way of showcasing and assessing student improvement in writing through their four years. Given the success of the writing initiative, we felt that QL could be approached in the same manner.

\section{The Evolution of an Idea}

Hiring of a new faculty member in math in 2003 stimulated a deeper look at our curriculum and initiated our foray into QL. In spring 2004, she met with faculty in other disciplines to assess students' preparedness for using quantitative information in those disciplines. The findings from these discussions were identical to those heard elsewhere: Students do not see the connections between mathematics and their chosen disciplines. Instead, they leave mathematics courses with a set of skills that they are unable to apply in non-routine settings and whose importance to their future careers they do not appreciate (Ganter and Barker 2004).

We combined these concerns with an analysis of student data. For seventy percent of our students, College Algebra or Topics in Liberal Arts Math was the terminal mathematics course taken to fulfill the liberal education requirement. Some students also took Introduction to Statistics, which is required by several majors, and less than ten percent of students took Pre-calculus or Calculus. This information prompted us to reevaluate the courses we offered in mathematics and to explore new approaches.

In summer 2004 a team of two faculty members, in mathematics and psychology, attended the Mathematical Association of America's Professional Enhancement Program (PREP) workshop "Quantitative Literacy Across the Curriculum: Everybody's Project," in Leavenworth, Washington. After the workshop, the team gave a presentation to a group of administrators, including the chair of the Department of Natural Sciences, the director of Liberal Education Program, and the Academic Vice President and Dean of Faculty. The presentation outlined the needs of the college in terms of developing students' mathematical skills, defined what Quantitative Literacy means, explained why the QL approach might be the right approach for us, and gave a list of other higher academic institutions that are actively involved in QL efforts.

Informal discussions following this meeting widened faculty interest. Five faculty members attended a second PREP workshop on QL at Macalester College in 2005. They included a biologist, a sociologist, a business professor, a professor in communications, and a mathematician. As part of refining the liberal education program, a group of faculty started to revise the Math proficiency mission statement. During discussions of the mission, it was clear that the ability to use technology to gather, analyze, and present quantitative information was going to be an important component. This prompted three faculty members, all in the 
Department of Natural Sciences but representing three disciplines, to apply to the first Spreadsheets Across the Curriculum Institute (SSAC) in Olympia, Washington. We also sent teams to this institute in 2006 and 2007. These teams have included professors in biology, chemistry, nursing, computer literacy, sociology, psychology, and business administration. Participants in these workshops became the "core group" that promoted QL on campus under the leadership of one of the authors (SK-B).

Interest has also been broad at workshops held on campus. In spring 2006, a faculty development seminar featured two of the SSAC participants describing their modules to the rest of the faculty. Also, in January 2006, we invited Caren Diefenderfer and Juergen Fleck from Hollins University for a faculty development seminar to formally introduce the idea of QL. This seminar attracted 25 faculty members (40\% of the faculty) including members from all seven departments. This strong support from our faculty colleagues, combined with support from the Academic Vice President, encouraged us to apply for funding from the National Science Foundation. Our now-funded project is designed to develop QL in a variety of disciplines. Its core method is summer faculty-development workshops, four days each, in which participants are awarded a stipend (Colby-Sawyer faculty members are on nine-month contracts). We thought that voluntary participation in spreading QL across the curriculum, enhanced by helping faculty include more QL elements in their classes, would work for us because of our history of faculty enthusiasm for new initiatives. Furthermore, we believed, a specific QL course requirement might have had less success because the recently revised liberal education program did not have much room for new requirements.

The first workshop was held in June 2007 and was attended by 23 faculty members representing six of the seven departments and 13 different disciplines. The purpose of this workshop was for faculty members to create QL materials for their classes (or adapt existing ones). These QL modules were made available to the rest of the college through our course management service and are published on the Colby-Sawyer College Web site ${ }^{2}$. Most of the modules are designed to be done in one or two class sessions with help from the instructor and perhaps a teaching assistant. Some are longer projects and most could also be done as homework. Several modules also involve some computer skills, mostly the use of spreadsheets, and as such are similar to modules created for SSAC ${ }^{3}$. Modulespecific cover material on the Web site identifies the relevant quantitative skills, the discipline and the context of each module.

The atmosphere at the workshop was one of imagination, creativity, and

\footnotetext{
${ }^{2}$ http://www.colby-sawyer.edu/academic/liberaleducation/quantitative/activities.html (accessed June 10, 2008).

${ }^{3}$ http://serc.carleton.edu/sp/ssac_home/index.html (accessed June 10, 2008).
} 
collaboration. Five QL experts from outside Colby-Sawyer made presentations and were available to help participants. The creativity and energy at the workshop is evident in some of the modules:

\section{Biology}

How long ago is "long ago"? - The evolutionary timeline

- Quantitative concepts: Proportions, large numbers, scientific notation.

- Students make a paper time line of geologic time, drawn to a consistent scale, then convert events in geologic history into months, days, hours, and minutes, by relating the history of the earth to a single year.

\section{Biology}

Magnification of a microscope

- Quantitative concepts: Proportions, unit conversion, algebraic equations, estimation, area.

- Students manipulate measurements of the field of view and magnification of different lenses of a microscope.

\section{Business}

Currency exchange

- Quantitative concepts: Percent change, unit conversion, graphing.

- Students use a table of currency conversions to calculate the cost of products, and graph the exchange rate over time to answer questions about the best times to buy and sell.

\section{Chemistry}

Enzyme kinetics

- Quantitative concepts: Rate of change, X-Y graphs, equation of a line, spreadsheet formulas.

- Students interpret a graph of the progress of a reaction and calculate the reaction rate at different concentrations of substrate. Then they manipulate variables in the Michaelis-Menton equation and graph the results.

\section{Early Childhood Education}

Did you attend a good elementary school?

- Quantitative concepts: Data analysis, graphs.

- Students compare ratings of schools. 


\section{Education}

Different ways of calculating a grade

- Quantitative concepts: Average, weighted average.

- Students calculate grades and then explore the effects of changing the weights of various assignments.

\section{English}

Fractals in poetry

- Quantitative concepts: Pattern recognition, fractals, functions in Excel®.

- Students learn about fractals and how they can be found in word repetition in poetry. They then use Excel ${ }^{\circledR}$ and perform word counts to identify patterns in two other poems. Finally, they write their own fractal poem.

\section{English}

Identifying a poet by the age of the words used

- Quantitative concepts: Frequency graphs, functions in Excel®.

- Students graph the frequency of the dates of origin of the words in Robert Frost's poems and then compare it to a poem by an unknown author.

\section{Environmental Studies}

Population growth, energy consumption, and $\mathrm{CO}_{2}$ production

- Quantitative concepts: Graphs, functions in Excel®.

- Students use Excel® to model the effects of changing population growth and per capita energy consumption on $\mathrm{CO}_{2}$ production.

\section{Political Science}

Who benefits from the tax reduction?

- Quantitative concepts: Mean, median, mode, weighted average, graphs.

- Students use a table from the Tax Policy Center that President Bush referenced to explain his 2004 tax break. They calculate median income, percent change in taxes, and compare the average tax break to a weighted average. They also graph some results.

\section{Psychology}

Data collection and analysis

- Quantitative concepts: Graphs, descriptive statistics, data analysis.

- Students design and carry out a health modification program to change an unwanted health-compromising behavior. They track the frequency of their target behavior over time and graphically analyze the data. 


\section{Sociology}

US census data analysis

- Quantitative concepts: Percent, percent change, solving equations.

- Students work with the US Census Bureau's American FactFinder Web site to gather data for a state or major city of their choice for 2005 and 2000. They then calculate the population differences as well as percent change for several variables using Excel@.

\section{Sociology}

Trends in divorce; comparing four way of calculating divorce rate

- Quantitative concepts: Percent, graphs, data analysis.

- Students calculate and graph four different measures of divorce rate using raw data from 1900 to the present. They discuss the advantages and disadvantages of each method and finally, read several examples of how all four rates are used in the media.

\section{Sociology}

Infant mortality rate

- Quantitative concepts: Mean, median, percent change, data analysis.

- Students review data from the 2006 Human Development Report and analyze the basic statistics (mean and median) of high humandevelopment, medium human-development, and low human-development countries. In addition they look at the percent change between 1970 and 2004 for selected countries and graph those changes.

\section{Writing}

Deductive and inductive logic in arguments

- Quantitative concepts: Logic.

- The instructor introduces logical terms and concepts and then asks students to apply these concepts to an argumentative essay they are writing and also to a peer's essay. Students also express the thesis of the paper in a logical equation and a Venn diagram.

Five other faculty members anticipate attending the next workshop in May 2008 and producing more modules.

The NSF grant also had a provision for developing new courses. As of 2008, our Topics in Liberal Arts Math course has been redesigned as a QL course and integrates the use of spreadsheets. By fall 2008, College Algebra will be redesigned as an algebra-based QL modeling course. Other new courses may follow. 


\section{Evaluation Plan}

A program that is spread across the curriculum is by definition, diffuse, and therefore difficult to assess and evaluate. Our evaluation plan has several components. We aim to evaluate the QL progress of the students; the change in faculty attitudes and in the curriculum; and the effectiveness of the modules used in classes.

\section{Evaluating Students' Progress}

We plan to evaluate the progress students have made in QL after encountering QL-focused activities in classes throughout their four years. The assessment for this evaluation plan has four parts: basic skills, basic QL skills, students' attitude towards mathematics/quantitative literacy, and applied QL skills.

To assess the first two skills sets, we developed multiple-choice tests. These assessment instruments were designed by adapting questions from existing tests and surveys, material in the textbook by Bennett and Briggs (2005), and by writing additional ones. Judith Moran from Trinity College, Dorothy Wallace and Jane Korey from Dartmouth College, Corrine Taylor from Wellesley College, Linda Kirstein from Bowdoin College, Mary O’Neil from Hamilton College, Caren Diefenderfer from Hollins University and Glenn Sproul from Johnson State College generously shared tests or survey materials with us. The original, compiled list of questions was edited so that each skill listed in our QL mission statement was addressed and a student could complete it in a reasonable amount of time.

The basic skills test covers mostly prerequisite skills (e.g., order of operations, arithmetic operations with fractions and decimals, proportions, basic descriptive statistics, and logic). The basic QL skills test assesses students' ability to apply the basic mathematical skills to problems they might encounter. Each test consists of 25 multiple-choice questions. Examples with results for our first-year students are shown in Table 1 (basic skills test) and Table 2 (basic QL skills test).

To assess student attitudes toward mathematics and QL, we developed a 20question survey. The questions aim to measure the effect of five factors: selfconfidence, anxiety, value, enjoyment, and motivation. Students respond on a Likert scale including: strongly agree, agree, neutral, disagree, and strongly disagree. Example questions with responses for our first-year students are shown in Table 3. 
Table 1. Example Questions on Prerequisite Skills

\begin{tabular}{|l|c|}
\hline \multicolumn{1}{|c|}{ Question } & $\begin{array}{c}\text { Percent of first- } \\
\text { year students who } \\
\text { gave the correct } \\
\text { answer }\end{array}$ \\
\hline Evaluate the following expression: $45+12 \times 5-36 / 3=$ & 49 \\
\hline Evaluate $(1 / 3)+(1 / 5)=$ & 53 \\
\hline $\begin{array}{l}\text { If the average of five numbers is 22, and four of these numbers } \\
\text { are: } 23,48,10, \text { and 14, find the value of the missing fifth number. }\end{array}$ & 46 \\
\hline $\begin{array}{l}\text { For the following scenario, decide if the conclusion is reasonable } \\
\text { from the information given. } \\
\text { Premise 1: You get a ticket whenever you park in front of the } \\
\text { "no parking" sign. } \\
\text { Premise 2: You got a ticket. } \\
\text { Conclusion: You parked in front of the "no parking" sign. }\end{array}$ \\
\hline
\end{tabular}

Table 2. Example Questions from the Basic QL Skills Test

\begin{tabular}{|c|c|}
\hline Question & $\begin{array}{l}\text { Percent of first-year } \\
\text { students who gave } \\
\text { the correct answer }\end{array}$ \\
\hline $\begin{array}{l}\text { In } 2004 \text { your salary increased by } 10 \% \text {. In } 2005 \text {, you received a } \\
10 \% \text { pay cut. After the two changes, how does your salary } \\
\text { compare to your original salary? } \\
\text { Answers: a) It is lower; b) It is higher; c) It has not changed; d) } \\
\text { The answer cannot be determined from the information given; e) } \\
\text { None of the above }\end{array}$ & 10 \\
\hline $\begin{array}{l}\text { The value of her house today is } 284 \% \text { more than when she } \\
\text { bought it. If she bought her house for } \$ 100,000 \text {, what is the } \\
\text { value of her house today? } \\
\text { Answers: a) It is almost } 400 \% \text { more than when she bought it; b) } \\
\text { It is almost } 300 \% \text { of the value when she bought it; c) It is almost } \\
4 \text { times what it was when she bought it; d) It is almost } 3 \text { times } \\
\text { what it was when she bought it; e) None of the above }\end{array}$ & 1 \\
\hline
\end{tabular}




\begin{tabular}{|c|c|}
\hline $\begin{array}{l}\text { The national debt is the amount of money owed by the } \\
\text { U.S. government. As of August } 30,2007 \text {, the U.S. national } \\
\text { debt amounted to almost } \$ 9 \text {-trillion. The population this } \\
\text { year is estimated to be approximately } 300 \text { million. Suppose } \\
\text { every person in America is asked to contribute an equal } \\
\text { amount to pay off the national debt. Estimate the debt per } \\
\text { person in } 2007 \text {. NOTE: In the U.S., } 1 \text { trillion is equal to } \\
1,000 \text { billion. } \\
\text { Answers: a) } \$ 30,000 ; \text { b) } \$ 3,000 ; \text { c) } \$ 33,000 \text {; d) } \$ 300,000 \text {; e) } \\
\text { None of the above. }\end{array}$ & 33 \\
\hline $\begin{array}{l}\text { Describe how you would structure a key word search to } \\
\text { find information on how World War II affected feminism } \\
\text { in either the United States or Europe (or both). } \\
\text { Answers: a) World War II AND feminism AND (United States } \\
\text { OR Europe); b) World War II OR feminism OR (United States } \\
\text { OR Europe); c) World War II and feminism AND United States } \\
\text { AND Europe; d) World Ward II AND feminism OR (United } \\
\text { States AND Europe); e) None of the above. }\end{array}$ & 37 \\
\hline $\begin{array}{l}\text { Children with elevated lead levels in their blood are typically } \\
\text { given high doses of iron (in the form of iron sulfide), because } \\
\text { iron displaces lead from vulnerable receptors in a child's } \\
\text { developing brain. The concentration of iron sulfide in this form } \\
\text { is } 15 \mathrm{mg} \text { for every } 0.6 \mathrm{ml} \text { of liquid. If a child needs } 75 \mathrm{mg} \text { of } \\
\text { iron sulfide per day, how much of the liquid (in ml) should the } \\
\text { child be given? }\end{array}$ & 55 \\
\hline $\begin{array}{l}\text { Answers: a) } 3 \mathrm{ml} \mathrm{b} \text { ) } 18.75 \mathrm{ml} \mathrm{c)} 8.3 \mathrm{ml} \mathrm{d}) 0.12 \mathrm{ml} \mathrm{e} \text { ) None of } \\
\text { the above }\end{array}$ & \\
\hline
\end{tabular}

Table 3. Example Questions from Attitude Survey

\begin{tabular}{|l|c|c|c|}
\hline & $\begin{array}{c}\text { Strongly Agree/ } \\
\text { Agree }\end{array}$ & Neutral & $\begin{array}{c}\text { Disagree/Strongly } \\
\text { Disagree }\end{array}$ \\
\hline $\begin{array}{l}\text { I feel confident about solving } \\
\text { problems that involve } \\
\text { numbers. }\end{array}$ & $57 \%$ & $28 \%$ & $15 \%$ \\
\hline $\begin{array}{l}\text { I do not need a good } \\
\text { understanding of mathematics } \\
\text { to achieve my career goals. }\end{array}$ & $27 \%$ & $21 \%$ & $52 \%$ \\
\hline $\begin{array}{l}\text { I view mathematics as an } \\
\text { obstacle to overcome in my } \\
\text { college studies. }\end{array}$ & $53 \%$ & $24 \%$ & $23 \%$ \\
\hline
\end{tabular}




\begin{tabular}{l|l|l|l|}
\hline $\begin{array}{l}\text { I get anxious when I am faced } \\
\text { with solving problems with } \\
\text { numbers. }\end{array}$ & $48 \%$ & $27 \%$ & $25 \%$ \\
\hline
\end{tabular}

Our evaluation plan is to administer the three tests to a sample of first-year and senior students. In fall 2007, the tests were administered to almost half of our first-year students in our interdisciplinary pathway seminars. This method relies on the collaboration of the 10-15 professors teaching these seminars. Despite several technical difficulties in the pilot of this program, we obtained results for 140 of approximately 300 first-year students. In spring 2008, we plan to administer the same instrument to students in the senior capstone class, again relying on collaboration from the professors teaching this class in 11 different majors.

We will continue to give the tests and surveys to first-year and seniors in the next three years. Even though most of these questions were compiled from existing tests we plan to do an analysis of the validity of the questions. Because individual students are identified, the comparison between first- and senior-year will show the effects of our program. We plan to compare the test scores for this four-year period, and explore any correlation between skills tests and grade point averages as a whole group and also within various majors. For first-year students, we also plan to explore the correlation between SAT scores and basic skills tests.

For the fourth part of our assessment plan for evaluating student progress applied QL skills - we will look for instances when students use a quantitative argument without being prompted, thus indicating a habit of mind. Specifically, we plan to develop a QL section for each student's electronic portfolio. This portfolio is Colby-Sawyer's main college-wide assessment tool; it is the way the college evaluates the success of both college-wide learning outcomes and writing across the curriculum. The QL portion of this portfolio asks students to identify one of the main issues we face, give a convincing argument that it is a problem, determine the magnitude of the problem, and propose a solution. So far, this assignment has been given only to first-year students in some introductory mathematics classes. Some of the issues students have identified are climate change, war, obesity, elections, and immigration. Our intention is to have students refine their answers to these questions each year so that the final product, we anticipate, will be a progression demonstrating increased presence and sophistication of quantitative arguments and QL skills. This part of the assessment is in its infancy. Its development depends on voluntary participation of many faculty members. 


\section{Evaluating Change in Faculty Attitude and in Curriculum}

We designed a survey to measure faculty attitude and comfort level towards quantitative issues and to learn whether faculty have integrated quantitative skills into their teaching and, if they have, which quantitative skills were addressed and to what degree. This survey was first administered at the beginning of summer 2007 and will be repeated in fall 2009 for us to quantify changes. We also surveyed the QL-related learning outcomes in all syllabi in spring 2006 and plan to monitor the change in syllabi for the next three years. We plan to track the number of courses that integrate a QL component into the class. We anticipate that the number of classes with QL components will increase.

\section{Evaluating the modules}

Each module includes a pre/post-test that directly addresses the quantitative skills in the module and their application. The test can be administered both before and after students complete the module to see if the students learned the skills. Some pre-planned classroom modules can be completed by students simply by following directions without understanding. This assessment makes sure that this has not happened.

\section{Contributors to Success}

At Colby-Sawyer College, we have engaged more than half of our faculty in QL across the curriculum in just a few years. Upon reflection, the characteristics of our college and the way in which we approached this project may have influenced our success. In particular, we believe all the following have contributed:

- From the onset, we involved as many people as possible and informed the entire faculty of what we were doing. We reported on the conferences we were attending, described our goals, and solicited input at faculty meetings. No change or proposal came as a surprise to the faculty or administration.

- The project was interdisciplinary from the beginning. Faculty members who attended workshops, presented on-campus seminars, and wrote the grant proposal were not mathematics faculty only. This discipline diversity is perhaps easier with a small faculty on a small campus, where informal conversations between classes or at lunch often center on difficulties students experience in our classes. Before our first 
presentation to the faculty, many had heard about QL from one of the core group.

- We have a culture of collaboration and innovation among faculty and staff at Colby-Sawyer. Accordingly, faculty members are willing to work together on problems that have been identified; they volunteer for new ventures, and they like the creative challenges of designing new curriculum and thinking about student learning. Participants in the workshops came from the full-time faculty as well as from the Academic Development Center, the Library, Residential Education, and Student Development. Workshops on writing across the curriculum were well attended and received positive reviews. Faculty perceived that it was our collective responsibility to teach writing, so it was not a big stretch for them to see that it was not up to the math faculty alone to teach QL.

- The administration not only supported; they participated. The core QL group includes the Academic Dean (now the coordinator of liberal education). The Academic Vice President provided institutional and financial support for the initiative. The president, in introducing the workshop in 2007, inspired participants with his description of why QL is so important and so appropriate for us.

- The faculty had focused time to concentrate on QL. The support of the NSF grant enabled work in summers when Colby-Sawyer College is not in session. Focused intellectual endeavors are difficult during semesters with heavy teaching loads (four courses per semester), and shorter summer workshops might have dampened enthusiasm. We felt it was important to engage faculty in a manner respectful of their other commitments, and funding of these workshops allowed this engagement. The support also allowed the QL group the time and funding to design and analyze the assessment and disseminate the modules on the Web. Additionally, it is assisting us in telling other institutions what we have learned.

- Colby-Sawyer College, like many colleges, includes scholarship of teaching as an option for meeting the scholarship criteria for promotion and tenure. A heavy teaching load usually precludes cutting-edge research in one's discipline, and we have attracted faculty who are truly interested in understanding and improving how students learn. It is a major focus of faculty intellectual energy. We believe this deep commitment to student learning is the reason why many pedagogical innovations are generated from small colleges. Of the 21 actual programs among the 32 "Selected Quantitative Literacy Programs in U. S. Colleges and Universities" (Steen 2007), 12 are at private liberal arts colleges under 3000 students.

In conclusion, our program is not unique. Many other colleges and 
universities have adopted QL programs that cross the curriculum and benefit from many of the advantages that we have at Colby-Sawyer College. For example, Carleton College's Quantitative Inquiry, Reasoning, and Knowledge (QuIRK) initiative $^{4}$, involves faculty development workshops that result in course redesign and classroom projects. Other colleges, Wellesley ${ }^{5}$ and Hollins ${ }^{6}$, for example, spread QL skills across the curriculum by requiring a course in a non-mathematics discipline in which QL skills are taught. Many colleges and universities include QL skills as part of their core or liberal education required courses. Undoubtedly, these institutions and the others with thriving QL programs have many of the advantages of setting and action we list for Colby-Sawyer. We believe the speed and extent of our progress derive from our having the combination of those advantages.

\section{Acknowledgments}

The authors are grateful to the other members of the QL team who not only helped on this manuscript but also made the program possible: John Callewaert, Lynn Garrioch, Joe Carroll, and Randy Hanson. Many other faculty members contributed to the design and execution of this program. This program was made possible by NSF DUE CCLI- Phase I grant, \#0633133. We thank the five Numeracy reviewers and editor Len Vacher for their helpful comments.

\section{References}

Bennett, J., and W. Briggs. 2005. Using and Understanding Mathematics: A Quantitative Reasoning Approach, $3^{\text {rd }}$ ed., Boston: Addison and Wesley.

Ganter, S. and W. Barker, eds. 2004. The Curriculum Foundation Project, Voices of the Partner Disciplines: A Collection of MAA Committee Reports. Washington DC: Mathematical Association of America. http://www.maa.org/ cupm/crafty/cf_project.html.

Gillman, R. 2006. Current Practices in Quantitative Literacy. Washington, DC: Mathematical Association of America.

Hughes-Hallett, D. 2001. Achieving numeracy: The challenge of implementation. In Mathematics and Democracy, ed. L. A. Steen, p. 93-98. Princeton, N.J.: National Council on Education and the Disciplines. http://www.maa.org/ q1/093-98.pdf

Hughes-Hallett, D. 2003. The role of mathematics courses in the development of quantitative literacy. In Quantitative Literacy: Why Numeracy Matters for

\footnotetext{
${ }^{4} \mathrm{http}: / /$ serc.carleton.edu/quirk/ (accessed June 10, 2008).

${ }^{5} \mathrm{http} / / / \mathrm{www} . w e l l e s l e y . e d u / \mathrm{QR} /$ (accessed June 10, 2008).

${ }^{6} \mathrm{http://www1.hollins.edu/homepages/hammerpw/qrhomepage.htm} \mathrm{(accessed} \mathrm{June} \mathrm{10,} \mathrm{2008).}$
} 
Schools and Colleges, p. 91-98. Princeton, N.J.: National Council on Education and the Disciplines. http://www.maa.org/q1/pgs91 98.pdf

Madison, B.L., and L.A. Steen, eds. 2003. Quantitative Literacy: Why Numeracy Matters for Schools and Colleges. Princeton, N.J.: National Council on Education and the Disciplines. http://www.maa.org/q1/qltoc.html.

Madison, B. L. and L.A. Steen. 2008. Evolution of Numeracy and the National Numeracy Network. Numeracy 1(1): article 2. http://dx.doi.org/10.5038/ $\underline{1936-4660.1 .1 .2}$

Richardson, R.M and W.G. McCallum. 2003. The third R in literacy. In Quantitative literacy: Why Numeracy Matters for Schools and Colleges, ed. B.L. Madison and L.A. Steen, p. 99-106. Princeton, N.J.: National Council on Education and the Disciplines. http://www.maa.org/q1/pgs99_106.pdf

Steen, L. A., ed. 2001. Mathematics and Democracy: The Case for Quantitative Literacy. Princeton NJ: The National Council on Education and the Disciplines. http://www.maa.org/q1/mathanddemocracy.html.

Steen, L.A. 2007. Selected Quantitative Literacy Programs in U. S. Colleges and Universities. http://www.stolaf.edu/people/steen/Papers/qlprogs.pdf. 